\title{
DIÁLOGO E COMPROMISSO SOCIAL: UM PERCURSO COM JOVENS DO CAMPO
}

\author{
Alexandra Maria Oliveira ${ }^{1}$ \\ José Levi Furtado Sampaio ${ }^{2}$ \\ Francisco Amaro Gomes de Alencar ${ }^{3}$
}

Resumo: O curso de formação sobre a Realidade Brasileira para Jovens Assentados e Acampados do MST Ceará é um momento de socialização de conhecimentos científicos necessários à vida social dos jovens do campo e tem por objetivo promover a formação a partir de discussões acerca das problemáticas que permeiam a realidade do espaço agrário cearense. E como procedimentos metodológicos, houve três momentos: o primeiro com a construção do curso; o segundo com a execução e o terceiro com a exposição dos resultados e avaliação final. $O$ curso tem sido trabalhado como um projeto em conjunto com o coletivo do Movimento dos Trabalhadores Rurais Sem Terra - MST e professores da Universidade Federal do Ceará - UFC. Em todos os espaços de formação do curso se percebe uma forte e importante integração entre os jovens acadêmicos e militantes que passam a se conhecer $e$ reconhecer no mundo da reforma agrária. Na travessia, o Movimento como organização social traz para o seio da universidade o debate geopolítico sobre saberes que se inserem na proposta da universidade aberta edemocrática, que permite romper e flexibilizar as barreiras impeditivas de acesso.

Palavras-Chaves: Juventude. Movimentos Sociais. Universidade.

\section{Dialogue and Social Engagement: A journey with rural youth}

\begin{abstract}
The "Training Course on the Brazilian Reality", ministered to the youth settler of the MST Ceará, is a necessary moment of socialization of scientific knowledge to the rural youth. The course has been worked as a joint project, assembling teachers of the "WithoutLand Movement" - MST and the Federal University of Ceará State - UFC, having as axe of discussion the political, economic and cultural formation, treated by the means of lectures, workshops, short courses and cultural evenings. In all spaces of the training experience, there was a strong and important integration among young people, who get to know and recognize the world of agrarian reform. In the process, the Movement as a social organization brings to the heart of the university the geopolitical debate about knowledges that are inserted in the proposal of an open and democratic university, what allows breaking down and relaxing barriers to its access.
\end{abstract}

Key-words: Youth, Social Movements, University.

\section{INTRODUÇÃO}

Os movimentos sociais têm lutado para que o acesso às universidades ocorra de forma democrática. Esse debate tem sido feito junto às instituições, principalmente acadêmicas,

${ }^{1}$ Universidade Federal do Ceará. Departamento de Geografia e área de Geografia e Ensino e Geografia Agrária. E-mail: alexandra.oliveira@ufc.br

${ }^{2}$ Universidade Federal do Ceará. Departamento de Geografia; Área de Geografia Regional. Email: joselevi@uol.com.br

${ }^{3}$ Universidade Federal do Ceará. Departamento de Geografia; Área de Geografia Agrária. E-mail: famaro@ufc.br DOI: 10.7154/RDG.2013.0026.0006 
organizações afrodescendentes, Movimento dos Trabalhadores Rurais Sem Terra (MST), Via Campesina e movimento indígena. Essas são organizações que mais têm intensificado a luta pelo acesso à universidade. Os resultados foram obtidos com a criação de cursos prévestibulares gratuitos para jovens carentes da cidade e do campo. Além desses, a luta continua na perspectiva de implementação de cursos superiores que atendam aos jovens assentados do MST e outros. Vários cursos foram criados no interior das universidades brasileiras: Pedagogia da Terra, Magistério da Terra, História, Agronomia, Direito, Comunicação e Agroecologia.

Seguindo essa perspectiva, o MST, juntamente com professores dos departamentos de Economia Doméstica e Geografia da UFC, a partir de experiências, criaram o curso de formação sobre a Realidade Brasileira para Jovens Assentados e Acampados do MST do Ceará.O evento tem por objetivo promover a formação de jovens do campo a partir de discussões acerca das problemáticas que permeiam a realidade do espaço agrário cearense, enfatizando a importância do papel da juventude na construção da reforma agrária no Brasil. E para implementação do curso houve três momentos: o primeiro com a construção do curso; o segundo com a execução e o terceiro com a exposição dos resultados e avaliação final. Os momentos acontecem de forma interativa, nos quais se considera a valorização do trabalho coletivo, a troca de experiências e o aprendizado entreos participantes.

Para o MST, o curso de formação é um momento de apropriação e socialização dos conhecimentos científicos necessários à vida pessoal e à vida social dos jovens do campo. Isso quer dizer que o curso é por natureza um lugar de teorias, mas com teorizações embasadas nas práticas sociais concretas em que os jovens assentados, estudantes, estejam envolvidos no dia a dia.

\section{O Percurso de Luta com os Jovens por um Projeto Popular para o Campo}

A luta pela reforma agrária no Brasil tem sido acompanhada pela reivindicação de melhores condições de vida nas áreas de assentamentos rurais. E entre as reivindicações, está a educação para o povo do campo.

Arroyo (2007), ao analisar políticas de formação de educadores do campo, revelou que as consequências da inspiração no paradigma urbano são marcantes na secundarização e na falta de políticas para o campo em todas as áreas públicas, na saúde e na educação de maneira particular. Um caminho alternativo tem sido apresentado pelos movimentos sociais 
que estão colocando na agenda politica dos governos, da sociedade e dos cursos de formaçãodois pontos básicos: o reconhecimento do direito dos diversos povos do campo à educação e a urgência do Estado assumir políticas publicas que garantam esse direito.

A análise da educação no/do campo passa, nos dias atuais por visõesinconciliáveis: o projeto oficial e o projeto popular. Um hegemônico, que acaba sendo pactuado porpolíticosque defendem o agronegócioe um popular, defendido pelos movimentos camponeses, que atende as necessidades do povo do campo.

No projeto oficial que é hegemônico na realidade brasileira, as políticas públicas para a formação específica de crianças, jovens e adultos do campo não fazem sentido. Como consequência, estamos diante de um quadro no qual os estudantes e profissionais da educação se deslocam cotidianamente para a escola, viajando por horas em estradas de terra, para estudar e trabalhar nas precárias e distantes comunidades rurais. Paralelamente, os estudantes e professores são alocados em salas de aula deterioradas ou improvisadas e, ainda, deslocados para a escola da cidade, para estudar com professores e colegas citadinos. Trata-se de uma política educacional que expressa total desrespeito às raízes culturais e identitárias dos povos do campo.

A desvalorização da escola rural se desdobra na insatisfação de alunos e professores com as duras condições de trabalho: salas de aula inadequadas, transporte escolar sem segurança, deslocamento dos alunos dos assentamentos para as escolas da cidade, para citar alguns exemplos. Destacamos que isso acontece em tempos de reafirmação do campo, através da presença política dos camponeses organizados em movimentos sociais.

A partir de 1990, podemos perceber que, no espaço rural brasileiro, tem-se estabelecido um projeto alternativo que de forma regular dinamiza luta por direitos, promovido por trabalhadores em representações como: a Confederação Nacional dos Trabalhadores da Agricultura (CONTAG), a Federação dos Trabalhadores da Agricultura (FETAG), a Federação dos Trabalhadores da Agricultura do Estado do Ceará (FETRAECE), a Comissão Pastoral da Terra (CPT) e o Movimento dos Trabalhadores Rurais Sem Terra (MST).

O sem-terra no Brasil e os zapatistas no México estão entre os quatro mais importantes movimentos sociais da América Latina. De acordó comSeoane (2003, p.13),

[...] los movimientos sociales de origen rural más importantes en la última década en Latinoamérica: el Movimiento de los Trabajadores Sin Tierra (MST) en Brasil, el movimiento cocalero del Chapare boliviano, la experiencia de la Confederación de Nacionalidades Indígenas del Ecuador, y el zapatismo en México. 
A consolidação desses movimentos sociais passam por princípios, organicidade e formas de ações que são recriadas e que se apresentam em uma nova configuração de protestos e no debate sobre as alternativas a favor dos povos do campo. A presença marcante dos semterra em rede nacional e internacional - não apenas reivindicando ser beneficiários de direitos, mas ser sujeitos, agentes históricos da construção dos direitos - incomoda a elite brasileira.

Nesse sentido, a falta de políticas públicas específicas de educação e a desestruturação das escolas rurais fazem parte de uma estratégia de desmobilização dos movimentos sociais do campo e de fortalecimento de um projeto de educação afinado entre Estado, Banco Mundial e elite agrária.

Na luta por um projeto popular de desenvolvimento do campo, os sem-terra expressam a concepção do direito à educação e do dever do Estado. No processo de luta pela reforma agrária, a posse e o uso da terra passam a ser condição para se viabilizar um conjunto de lutas, entre outras: luta por escolas e formação de qualidade, por educação contextualizada, por estrutura viária básica. Esse é um fato extremamente relevante na compreensão dos processos políticos e sociais que envolvem a escola do campo. De acordo com Fernandes (2006), foi da demanda específica por educação nos acampamentos e assentamentos do MST que nasceram o Programa Nacional de Educação na Reforma Agrária (Pronera) e a Coordenação Geral de Educação do Campo.

Carvalho (2006), ao analisar o Pronera no Ceará, reafirmou o fato de os movimentos sociais do campo na luta pela garantia do direito à educação passarem a reivindicar de forma expressiva, a partir de meados da década de 1990, junto ao governo federal, uma política educacional pública que viesse atender as necessidades da classe trabalhadora rural. Em 1998, foi criado o Pronera, vinculado ao Ministério de Desenvolvimento Agrário.

Dessa forma, a educação do campo deve ser compreendida como um processo em construção que contempla, em sua lógica, a política que pensa a educação proposta pelos sem-terra como parte constitutiva e essencial para o desenvolvimento do campo a partir do projeto popular.E tem se consolidado, conforme Fernandes (2012), como política emancipatória em constante luta pela democratização do conhecimento para umamaior parcela de pessoas.

A leitura midiática sobre ensino, juventude e educação no Brasil está sempre amarrada aos baixos índices de rendimento, às altas taxas de analfabetismo e à evasão escolar. Problemas 
relacionados ora a questões sociais, como a fome e a miséria, ora a questões econômicas, como a falta de emprego e a não qualificação entre os jovens, sempre estão em pauta. Entretanto, para Martins (2008), as notícias sobre o ensino e a educação no Brasil nem sempre tocam no essencial. As preocupantes adversidades pouco tratam do fato de que há no país um generalizado apreço pela vontade de aprender, visto muitas vezes em lugares de absoluta ausência do poder público. Muito do que existe como valorização da escola rural é, sem dúvida, em grande parte um êxito da escolarização promovida pelo MST, apesar dos conteúdos pedagógicos discutíveis e dos simplismos ideológicos, particularmente da escola rural. O movimento tem suprido carências de saber com criatividade e conservado a utopia da universalidade do ser e do direito. Isso acontece, sobretudo, porque a ideologia educacional do MST tem a coerência que falta à ideologia sindicalista dos professores da rede pública e privada de ensino: a escola dos sem-terra liga-se ao projeto utópico de um modo de vida viável e que representa uma resistência legítima às diferentes forças que, em nome da grande economia multinacionalizada e voraz, nulificam valores, crenças, maneiras de viver e capitais sociais acumulados ao longo dos séculos.

\section{A Construção do Diálogo e Compromisso Social com os Jovens do Campo}

Para que o processo de luta pela reforma agrária seja uma conquista plena, é preciso pensar a educação na relação escola, trabalho e cooperação. Esse é mais um dos princípios do setor de educação: a Escola do Trabalho. Para o MST (2001), escola do trabalho quer dizer escola do trabalhador, da classe trabalhadora. E essa é uma marca que faz diferença no conjunto das lutas do movimento. As crianças, os jovens e adultos precisam ser educados como trabalhadores para que possam ser trabalhadores capazes de transformar o conjunto da sociedade. Se não for assim, a luta vai pela metade.

$\mathrm{Na}$ direção da construção da relação escola, trabalho e cooperação, fortaleceram a troca entre universidade e movimentos sociais através dos cursos estaduais de formação sobre a Realidade Brasileira para Jovens Assentados e Acampados do MST Ceará.

Para Freire (2001), o aprendizado da leitura e da escrita, na construção do processo de expressividade, não terá significado real se se faz através da repetição mecânica de sílabas. Esse aprendizado só é válido quando, simultaneamente com o domínio da formação vocabular, o educando vai percebendo o sentido da linguagem. Quando ele vai percebendo a relação entre linguagem-pensamento e realidade. A transformação da realidade, ao exigir 
novas formas de compreensão, coloca também à necessidade de novas formas de expressão.

Tal é o caso da constituição do curso com os jovens do campo. O que antes era área de "latifúndiodo saber", hoje, enquanto espaço de democratização do conhecimento, caracteriza-se como espaço de diálogo e de possiblidades para filhos de trabalhadores do campo. Os movimentos sociais em parceria com a universidade vêmtransformandoa estrutura do "latifúndio do saber", e isso tem resultado em novas formas de expressão e de pensamento.Nesse contexto, a organização curricular do curso tem por base a pedagogia Freiriana que entende a educação como prática de liberdade e transformação.

De acordo com Lima et al (2004), para o MST, o curso de formação deve garantir a apropriação e socialização de conhecimentos científicos necessários à vida pessoal e à vida social. Isso quer dizer que o curso não pode ser somente de teorias nem também somente de prática.O curso é por natureza um lugar de teorias, mas o que se defende é que as teorizações tenham como base as práticas sociais concretas em que os jovens estudantes estejam envolvidos.

No cumprimento de seu papel de formadora de consciências críticas, a Universidade Federal do Ceará, através da Pró-Reitoria de Extensão (PROEX), implementa diversas ações para ampliar os vínculos com os movimentos sociais. Nesse caminho, o curso sobre a Realidade Brasileira para Jovens Assentados e Acampados tem sido desenvolvido como projeto de extensão executado pelo Laboratório de Estudos Agrários e Territoriais (LEAT) e do Núcleo de Estudos de Gênero e Família (NEGIF) vinculados aos departamentos de Geografia e Economia Doméstica da UFC, respectivamente, desde o ano de 2001. O curso tem a característica de ser trabalhado como um projeto em conjunto, ou seja, MST-CE, professores e alunos do LEAT e NEGIF discutem no decorrer de cinco meses as atividades que antecedem o curso: preparação, organização e execução.

O processo metodológico se deu através de três momentos: primeiro, preparação do encontro que consiste da formação da equipe de trabalho, que é composta por uma coordenação geral e coordenações de área que ficam com responsabilidades específicas: infraestrutura; programação; oficinas; apresentações culturais; alimentação; comunicação; finanças e secretaria. Compete aos organizadores, em especial, dos movimentos mobilizar os jovens do campo, durante o período que antecede a realização do evento. As reuniões entre professores e representantes das organizações envolvidas têm início concomitantemente com o calendário acadêmico e se estendematé o final do ano letivo; segundo, ocorre o 
desenvolvimento do curso, no qual os jovens do campo participantes são divididos em grupos (brigadas) entre os quais são distribuídas atividades de manutenção, organização do ambiente e faxina dos alojamentos. A responsabilidade pela organização do ambiente, portanto, é compartilhada entre os próprios jovens. Nesta fase, pelas manhãs, são proferidas palestras em formato de mesa redonda, seguidas de debates. Às tardes, são realizadas as oficinas com troca de experiências. No período noturno, acontecem as apresentações culturais de grupos musicais, danças, filmes e teatro. No terceiro momento, acontece a exposição e a avaliação do que foi produzido e ocorreu durante o evento que substancia a elaboração do relatório final.

De maneira geral, o MST escolhe os jovens que irão participar do curso por brigadas e prepara-os em encontros regionais alertando sobre a disciplina nos horários e nas atividades, o compromisso social e a importância do trabalho coletivo, como expresso na fala:

Através do dirigente de minha brigada, Che Guevara, fui convidado [...] neste encontro me despertou o interesse de estar vindo e estou bastante feliz pois é de tamanha importância. (Assentada, 21 anos, Che Guevara, 2009).

Um segundo depoimento afirma que:

A direção da brigada nos proporcionou um encontro com os jovens da brigada Che Guevara e ali escolheram os jovens dos assentamentos para o encontro Estadual. (Assentado, 14 anos, Che Guevara, 2009).

Como militantes, é preciso que os jovens desenvolvam, a partir da participação nesses eventos, a capacidade de multiplicar os conhecimentos apreendidos em diversos espaços de formação presentes no curso e possam contribuir com a organicidade do movimento. A formação política dos jovens, entendida como um dos objetivos, é trabalhada através de embasamentos científicos, políticos, sociais e culturais apresentados por especialistas de diversas áreas (geógrafos, sociólogos, economistas domésticos, historiadores, entre outros) e militantes da representação nacional do movimento.

O público do evento são os jovens assentados que possuem um perfil bem próximo ao descrito por Sales (2007), ou seja, jovens (rapazes e moças) provenientes de áreas de assentamentos rurais que compõem a faixa etária com menos de 20 anos, e que estão conscientes da importância da permanência na escola. Muitos sonham em ter acesso à universidade ou concluir um curso técnico profissionalizante, ou ser professor para melhorar as condições de vida e do assentamento. 
Na organização do curso, há muitos jovens que cursaram etapas anteriores do curso e hoje estão cursando ensino superior nos cursos de formação para assentados. Para os jovens, o sonho de conseguir nos assentamentos melhores condições de vida é fortalecido com o acesso à educação e à organização política.

Conforme Sales (2007), isso não impede a existência de ambiguidades no cotidiano desses jovens. Muitas vezes, o mundo real, que consiste no trabalho da roça, nos afazeres domésticos e nas viagens diárias a pé para a escola, é barrado no final do dia pelo mundo ideal e colorido das telenovelas. Mesmo assim, podemos dizer que, apesar de muitos dos jovens cultivarem o sonho de ir para a cidade, outros estão alimentando o sonho de conseguir nos assentamentos melhores condições de vida. A conquista do assentamento trouxe para os jovens a esperança da autonomia. A opção por ficar no campo tem revelado uma alternativa de luta, ou seja, é preciso lutar cotidianamente para ter condições de sobreviver na terra conquistada.

O curso de formação sobre a Realidade Brasileira para Jovens dos assentamentos do Ceará MST/UFC tem sido tradicionalmente realizado no mês de julho de cada ano no campus do Pici em Fortaleza. Tem como eixos de discussão a formação política, econômica e cultural. 0 evento, geralmente, é aberto com uma mística que representa ligação das lutas propostas com o mundo espiritual no sentido de fortalecer a agregação entre indivíduos que formam o movimento, e também na constituição de um momento em que a interação vai além das fronteiras políticas e ideológicas do movimento porque traz para junto outros indivíduos que se solidarizam com a luta por uma mudança na sociedade. A mística é um momento reflexivo sobre a espiritualidade e a agregação nas lutas, e em especial, o encontro de jovens.

Na sequência, o eixo de formação política é debatido inicialmente na apresentação da conjuntura nacional desenvolvida por um representante da direção nacional do MST. Nesse momento, o palestrante procura abordar os vários cenários da expansão do capitalismo nos setores econômico, político, social, ecológico, alimentar e energético. Temas que estão presentes na geografia capitalista e necessitam ser introduzidos na geografia camponesa, enfocando a importância da juventude organizada e a compreensão de sua vulnerabilidade, e discutindo o desafio de repensar a condição camponesa nas lutas e conquistas sociais no Brasil, como, por exemplo, as conquistas relacionadas à posse e ao uso da terrae a educação e cultura nos assentamentos. 
Além do momento de análise conjuntural, são construídos debates que trazem particularidades que fortalecem as lutas do campo, a exemplo do pensamento de alguns dos intelectuais e líderes que inspiram o movimento,como Florestan Fernandes e Che Guevara. A discussão sobre gênero e juventude no campo estão presentes porque pensar a participação das mulheres nas organizações sociais é parte da vida cotidiana dos assentados. Também a discussão sobre a história social camponesa é vista como representação simbólica porque serve para fortalecer a atualidade da juventude. No que tange à formação econômica, o debate é feito em torno do projeto camponês que disputa espaços e territórios com o projeto do agronegócio.

Seguindo o conteúdo programado nos encontros de jovens, são construídas oficinas demandadas pelo movimento a partir de reuniões de base com as brigadas de que fazem parte os assentados e acampados.

\section{Oficinas relativas a atividades econômicas e culturais}

Apicultura - ensina a trabalhar com as colmeias e produzir mel. Nesse momento, os jovens aprendem a construir as colmeias, a lidar com as abelhas, identificando as floradas do semiárido e as mais importantes para a produção de mel de boa qualidade. Além desses aspectos, os alunos adquirem técnicas de coleta do mel de forma higiênica.

Piscicultura - prepara os alunos para trabalhar com viveiros de peixes, gaiolas e pescar de forma racional sem contaminar as águas. Durante a oficina, são apresentados os tipos de peixes usados nos açudes e barragens que podem ser utilizados como alimento e fonte de renda familiar.

Cooperativismo - debate a história do associativismo, com destaque para o cooperativismo, esclarecendo como se constrói uma cooperativa, (agropecuária, de crédito) e também discutindo os princípios do planejamento e da gestão.

Agroecologia- discute a relação sociedade e natureza no semiárido, de forma que seja percebida pelos jovens camponeses a importância da agroecologia para as famílias no campo. Também estuda essa modalidade de agropecuária como um modelo que se contrapõe ao hegemônico e que garante a vida saudável dos camponeses e dos consumidores em geral. 
Customização - ensina a utilizar a reciclagem com retalhos e roupas usadas. Durante a oficina os alunos aprendem a cortar, costurar, pintar e reciclar roupas e cortes de tecido, confeccionando blusas com símbolos, bolsas, tapetes, bonecas, entre outros artefatos.

\section{Oficinas relativas à arte e cultura}

Violão - ensina a tocar violão. Durante cada encontro, os jovens estudam a leitura de partituras, aprendem a identificar as notas musicais e exercitam tocando músicas relacionadas aos ideais do movimento.

Percussão - ensina a tocar zabumba, prato, triângulo, maracá, chocalho, reco-reco e outros instrumentos. Nessa oficina, debate-se sobre as músicas afro, indígenas e camponesas. Os alunos aprendem também a cantar e a dançar essas melodias.

Ciranda - vivencia a ciranda como cultura. Durante a oficina,conta-se a história da ciranda,explicandoem que regiões ou cidades do Brasilela estámais presente na cultura dos lugares. Os jovens aprendem a dançar, cantar e, ao final, apresentam e integram todos nas rodas de ciranda.

Nas oficinas de violão, percussão e ciranda, os jovens começam a entender e a diferenciar os diversos ritmos musicais existentes no interior do Brasil e ao mesmo tempo fazer a sincronia e a harmonia dos sons.

Bonecos (mamolengos) - essa oficina dá oportunidade aos alunos de construir diversos tipos de bonecos usando como matéria-prima madeira, pano, papelão e garrafa plástica. Durante os trabalhos, são produzidos roteiros de peças, que são ensaiadas e reproduzidas no final do encontro. O mamolengo é uma brincadeira, uma arte popular que existe no interior do Nordeste feita principalmente por camponeses que representam o cotidiano, hoje muito utilizada para repassar conhecimentos às crianças, jovens e adultos. Essa arte transformouse em instrumento na luta dos movimentos sociais, daí sua inclusão no encontro de jovens assentados.

Grafite - nessas oficinas, os jovens aprendem que esse tipo de arte é de grande valia para extravasarem a criação, expondo os sentimentos e as emoções através dos desenhos que fazem no decorrer do encontro. Nos últimos encontros, foram produzidos vários painéis representativos do cotidiano da política e dos jovens. 


\section{Oficinas referentes à saúde e à educação}

Saúde e ambiente - nessa oficina, é apresentada aos participantes a relação que existe entre a saúde e o território onde habitamos. Traz à tona a concepção de epidemiologia e as doenças que adquirimos com o uso de agrotóxicos. Aborda os alimentos contaminados e aconselha os alunos a produzirem agroecologicamente.

Leituras e produção de texto - oficina cujo objetivo é fazer com que os jovens participantes aprendam a ler e escrever textos simples, ao ministrar aulas de leitura e produção de texto. É uma metodologia que faz os alunos se envolverem de forma coletiva na discussão de textos que facilitam a apreensão do conhecimento, da linguagem e da produção, capacitando-os a fazer uma apresentação teatral dos textos ao final do curso.

Rádio e comunicação - aqui os jovens discutem os fundamentos da comunicação popular e as técnicas de rádio: informação, comunicação e conhecimento. Aprendem que a informação é passada para os ouvintes via rádio e pode ser transformada pelo receptor em conhecimento, consolidando um processo de construção da consciência. Sempre ao final do curso, é apresentada à plenária um programa de rádio estruturado pelos alunos falando sobre a vida rural.

Como vimos, as oficinas são práticas refletidas realizadas durante o encontro de jovens com o objetivo de colaborar na construção da organização dos assentados e na confecção de produtos nos assentamentos voltados à geração de renda. Não possuem um cunho estritamente prático, porque são pensadas na interação política, social, econômica e cultural.

É através das oficinas que os jovens expõem seus potenciais artísticos, contribuem para reproduzir conhecimentos do senso comum que estão latentes nos processos culturais da sociedade camponesa e que emergem durante os encontros de jovens. Além da criatividade revelada, os alunos aprendem a construir objetos que serão posteriormente transformados em fonte de renda familiar. Outro aspecto importante das oficinas são as aprendizagens significativas ao construir atitudes diferenciadas com o meio ambiente, na elaboração de projetos de crédito, na organização de cooperativas e ao despertar para a leitura, a música, o teatro de boneco, habilitando os jovens a construir seus próprios produtos e roteiros das peças. 
Verificamos que as oficinas são verdadeiras terapias ocupacionais em que todos estão ligados, descobrindo, refletindo e construindo, de forma interativa, conhecimentos que serão levados para os assentamentos.

Outro momento divertido e de encontros são as apresentações culturais, que reúnem cantores da terra, teatro de bonecos, cirandas e quadrilhas juninas. Em todos os espaços, se percebe uma forte e importante integração entre os jovens, que passam a se conhecer e reconhecer no mundo da reforma agrária.

Esse encontro de jovens do campo tem contribuído significativamente na formação política, econômica e cultural da juventude camponesa, conforme diversos relatos:

Aprendemos que nem sempre sabemos valorizar as nossas riquezas do campo. Como se dá a corrupção da mídia e do sistema capitalista. Vemos também a importância do papel da juventude, perante a nossa realidade: como droga, violência, meio ambiente (Assentado, Lagoa do Mineiro, 2009).

Aprendi muito, como o Brasil precisa de mudanças nos meios políticos, sociais, também como nós. Sentimos necessidade de estar organizados. Com o encontro vivenciamos troca de experiências com os jovens de outras regiões. Aprendemos novas coisas, a se desafiar consigo mesmo (Assentado 22 anos, Zumbi dos Palmares, 2009).

Eu vivenciei muitas coisas boas e ruins também o que eu aprendi que o movimento sem terra está aumentando cada vez mais e isso é muito bom porque só assim muitos trabalhadores pobres terão um futuro melhor para seus filhos (Assentada, 27 anos,Santa Luzia, 2009).

Esse é meu primeiro encontro e eu aprendi muito; vou passar o que aprendi para meus companheiros que não puderam vir a esse encontro. (Assentado, 16 anos, Baixa Verde, 2009).

As falas apresentadas versam sobre conjuntura nacional, organização política, formação da juventude, diálogo, respeito e compromisso social. Essas falas foram fundamentais para os encaminhamentos na perspectiva da continuidade da realização do curso, entendido como um instrumento eficaz no trabalho de entendimento da realidade social presente no campo brasileiro.

\section{CONSIDERAÇÕES FINAIS}

O movimento como organização social traz para o seio da universidade o debate político sobre os saberes que se inserem na proposta da universidade popular, democrática, que permite romper eflexibiliza as barreiras impeditivas de acesso. 
O sentido do curso de formação para jovens tem sido significativo para a concretização da flexibilização política no que tange à entrada na academia de novos sujeitos sociais que até então não tinham como participar.

No desenvolvimento do curso, a disposição para aprender tem sido algo visto nos rostos e nas práticas dos jovens participantes que têm presença maciça nos diferentes momentos de formação e no esforço contínuo de militantes e professores para levar algo novo para as salas de aula. A gestão do curso tem sido feita cuidadosamente mesmo durante o evento, através de reuniões diárias trabalhadas no sentido de verificar o andamento das atividades e o cumprimento das tarefas propostas pelas brigadas. A busca pela qualidade na formação dos jovens se releva em diferentes momentosatravés: das condições dignas de trabalho docente; do acesso ao material didático pelos discentes e do desenvolvimento de saberes alternativos que contribuem para novas formas de cultura e de compreensão do mundo.

A espacialização do movimento nas suas brigadas regionais tem conduzido de forma eficiente e com competência as orientações norteadoras de uma consciência social sobre o papel da universidade como instituição formadora de sujeitos sociais críticos e participativos. A Geografia como campo do conhecimento científico, juntamente com economistas domésticos, tem sido elo, parte da corrente de rompimento das barreiras rígidas que formam a estrutura da universidade.

$\mathrm{Na}$ travessia, a relação movimentos sociais e universidade tem revelado ganhos sociais irreversíveis. Os pesquisadores têm feito o esforço de contribuir cada vez mais com leituras sobre a realidade social vivida no campo brasileiro. Espera-se que essas leituras possam contribuir para a conquista de novos espaços de luta pela reforma agrária. A conquista de espaços de ensino, pesquisa e extensão pelos movimentos se ampliam na caminhada e está fortalecendo a opção por um projeto popular de educação com e para o povo do campo.

\section{REFERÊNCIAS BIBLIOGRÁFICAS}

ARROYO, Miguel Gonzalez. Políticas de formação de educadores(as) do campo. Cadernos do Cedes 72, Educação do Campo, maio/ago, 2007, São Paulo, Cortez, Campinas, Cedes, 2007, p. 157-176.

CARVALHO, Sandra M. G. de. Educação do campo: Pronera, uma política pública em construção. 2006. Tese (Doutorado em Educação) - Programa de Pós-Graduação em Educação da Universidade Federal do Ceará - UFC, Fortaleza, 2006.

FERNANDES, Bernardo Mançano. Os campos da pesquisa em educação do campo: espaço e território como categorias essenciais. In: MOLINA, Mônica Castagna. Educação do campo e 
pesquisa: questões para reflexão. Brasília: Ministério do Desenvolvimento Agrário, 2006, p. 27-39.

Reforma agrária e educação do campo no Governo Lula. In: CAMPOTERRITÓRIO: revista de geografia agrária, v.7, n.14, p.1-23, ago.,2012.

FREIRE, Paulo. Ação cultural para a libertação. Paz e Terra. São Paulo, 2001.

LIMA, Anna Érika Ferreira et al. Cursos estaduais de formação sobre a realidade brasileira para jovens do MST - CE: uma análise da terceira edição. In: ENCONTRO NACIONAL DE GEOGRAFIA AGRÁRIA, 17, Anais... 2004. Gramado/RS: Ed. URGS, 2004.

MARTINS, José de Souza. A educação, entre o balcão e o ensino. $\mathbf{O}$ Estado de $\mathbf{S}$. Paulo,Caderno Aliás, A Semana Revista, domingo, 30 de março de 2008, p. J5.

MST. Dossiê MST escola. Documentos e estudos 1990-2001.Edição especial. São Paulo: Expressão Popular, 2005.(Caderno de Educação, n. 13).

SALES, Celecina de Maria Veras. Gênero e geração no âmbito dos assentamentos rurais e da reforma agrária. In: SALES, et al. (Org.). Terra, sujeitos e condição agrária. Fortaleza: Imprensa Universitária, 2007.p. 79-100.

SEOANE, José (Compilador). Movimientossociales y conflicto em América Latina. Buenos Aires: Clacso, 2003.

Artigo recebido em 07/02/2013.

Artigo aceito em 07/06/2013. 